\title{
Convective Heat Transfer in a Pneumatic Hybrid Engine
}

\author{
P. Brejaud*, P. Higelin, A. Charlet, G. Colin and Y. Chamaillard \\ Université d'Orléans, Institut Prisme, 8 rue Léonard de Vinci, 45072 Orléons Cedex 2 - France \\ e-mail: pascal.brejaud@univ-orleans.fr - pascal.higelin@univ-orleans.fr - alain.charlet@univ-orleans.fr-guillaume.colin@univ-orleans.fr - \\ yann.chamaillard@univ-orleans.fr \\ * Corresponding author
}

\begin{abstract}
Résumé - Échange de chaleur convectif dans un moteur hybride pneumatique - Plusieurs études ont déjà montré que le concept d'hybride pneumatique est une alternative techniquement et économiquement viable à l'hybridation électrique. Malgré l'absence de combustion lors d'un fonctionnement en mode entraîné ou pneumatique, les échanges de chaleurs convectifs restent un facteur de premier ordre sur un bilan énergétique. Il faut donc disposer d'un modèle précis d'échange de chaleur instantané afin de prévoir la pression instantanée dans un cylindre du moteur. Cette étude montre que, à cause de l'extinction du mouvement de tumble à l'approche du point mort haut, la forme originale du modèle de Woschni n'est pas adaptée, pour un moteur opérant en mode pneumatique entraîné, à décrire la forme mesurée des échanges de chaleurs instantanés en fonction de l'angle vilebrequin. Les auteurs proposent une modification du modèle de Woschni décrivant plus fidèlement les échanges de chaleurs instantanés lors des courses de compression et de détente, applicable pour les modes pneumatique et entraîné avec coupure d'injection. En premier lieu, le nouveau modèle à paramètres constants est identifié à partir de mesures expérimentales effectuées en mode entraîné sous diverses conditions opératoires. Le mode suralimentation pneumatique sans combustion (allumage non déclenché) est alors étudié, en utilisant des valeurs de paramètres identiques à celles utilisées en mode entraîné. Cette étude montre que le modèle modifié reste pleinement applicable au mode suralimenté, et ceci malgré une certaine modification de la structure aérodynamique interne du cylindre créée par l'ouverture de la soupape de charge sous un haut rapport de pression.
\end{abstract}

\footnotetext{
Abstract - Convective Heat Transfer in a Pneumatic Hybrid Engine - Several previous studies have proven that pneumatic hybridization of an internal combustion engine is a technically viable and cost-efficient alternative to electric hybridization. Because the heat transfer process remains a first order factor while the engine operates in a motored or pneumatic mode without combustion, an accurate instantaneous heat transfer model is required in order to predict the in-cylinder pressure. This study shows that the original Woschni model is not suitable for describing the shape of the measured instantaneous heat flux versus crank angle while the engine operates in a motored pneumatic mode, because of the extinction of tumble motion near Top Dead Center (TDC). A modified form of the Woschni model is therefore proposed here that better describes the instantaneous heat flux during compression and expansion strokes, applicable to pneumatic and motored with fuel cut-off modes. First, the new constant parameter model is identified from experimental measurements performed in various motored mode conditions. Next, the pneumatic supercharged mode without combustion (ignition not performed) is investigated with the new model using the same identification values as for the motored
} 
mode. This study shows that the modified model remains fully applicable to the supercharged mode, despite of a certainly modified in-cylinder aerodynamic structure created by the opening of the charging valve under a high pressure ratio.

\section{Notations}

Re Reynolds number

$\mathrm{Nu} \quad$ Nusselt number

$S t \quad$ Stanton number

$U \quad$ Internal energy

$W \quad$ Mechanical work

Q Heat

$H \quad$ Enthalpy

$h \quad$ Convective heat transfer coefficient

$w \quad$ Average cylinder gas velocity

$m \quad$ Air mass

$T \quad$ Temperature

$p \quad$ Pressure

$V \quad$ Volume

$C, C_{1} \quad$ Woschni tunable coefficients

$\mathrm{k}$ Thermal conductivity

$\mu \quad$ Dynamic viscosity

\section{Superscripts}

pred Predicted

stand Standard Woschni model

mod Modified Woschni model

\section{Subscripts}

g Gaz

$w \quad$ Wall

$r \quad$ Reference

int Intake

chy Charging

exh Exhaust

tank Air tank

\section{Acronyms}

CA Crank Angle

TDC Top Dead Center

IVO Intake Valve Opening

IVC Intake Valve Closing

CVO Charging Valve Opening

CVC Charging Valve Closing

EVO Exhaust Valve Opening

EVC Exhaust Valve Closing

NRMSE Normalized Root Mean Square Error

RPM Revolutions Per Minute

\section{INTRODUCTION}

In order to reduce pollutant and greenhouse gas emissions, Internal Combustion Engines (ICE) have to constantly improve their mean efficiency.

The first problem of ICE is that peak efficiency is obtained near full load. The consumer demand for high

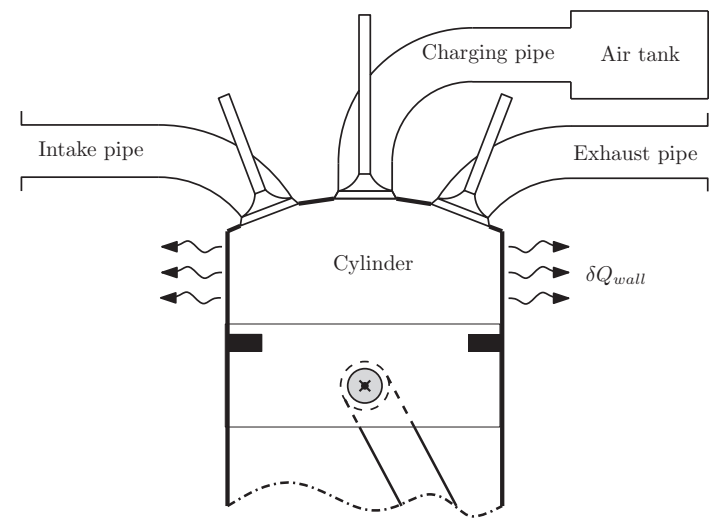

Figure 1

Schematic representation of a single cylinder pneumatic hybrid engine.

maximum power and torque leads to increasing engine displacement, thus to decreasing mean efficiency at part load which corresponds to real life driving conditions. This drawback can be tackled by downsizing the engine while keeping a high maximum power with the use of a turbocharger. However, this in turn creates the problem of "turbo-lag" during a strong acceleration transient phase. The turbocharger inertia limits its rotational acceleration, and hence the supercharging capacity of the engine.

The second problem is that vehicle braking energy cannot be transformed back into re-usable energy. This shortcoming is tackled with the hybridization concept, such as the electric hybrid vehicle.

Another alternative is pneumatic hybridization, which provides a smart answer to both of the above-mentioned problems. The concept of the pneumatic hybrid engine, which has been investigated by several research groups [1-6], is based on a conventional internal combustion engine in which one additional valve, called the charging valve, connects the combustion chamber to an air tank as shown Figure 1. Intake and exhaust valves can remain camshaft-driven, and only the charging valve is moved by a fully variable actuator. As a result, the new major modes allowed by this additional valve (pneumatic pump, pneumatic motor and supercharged) remains 4-Strokes cycles [7].

Pneumatic Pump: This mode transforms vehicle kinetic energy into a re-usable pneumatic energy. The cycle begins with a conventional intake stroke. The charging valve opens during the compression stroke as soon as 
the in-cylinder pressure reaches that of the charging port. The valve closes shortly after TDC, and the cycle finishes with conventional expansion and exhaust strokes.

Pneumatic Motor: This mode is used to transform pneumatic energy into mechanical work without any combustion. The cycle begins with classical intake and compression strokes. The charging valve opens when approaching TDC, and remains open during part of the expansion stroke in order to maintain pressure at a high level and generate the desired indicated work. The cycle finishes with a conventional exhaust stroke.

Pneumatic Supercharged Mode: This mode is used to compensate for the "turbo lag" effect, while temporarily boost the engine during a strong acceleration transient. The charging valve opens shortly after intake valve closure, and closes when the desired additional air mass has flowed into the in-cylinder. The end of the cycle remains the same as a conventional four stroke one.

Several previous publications [3,7-9] have shown that the concept of a pneumatic hybrid engine could provide benefits in terms of fuel consumption and greenhouse gas emissions that are comparable with those of an electric hybrid vehicle [10], but with lower weight and presumably lower cost.

This paper focuses on a convective heat transfer model while operating in a motored with fuel cut-off or pneumatic modes for two reasons.

The first is that despite the absence of combustion during a pneumatic cycle, an energy balance applied to experimental data constantly shows that heat transfer remains a first order factor. See Sections 3 and 4. Thus, to accurately predict mechanical performances, a heat exchange model which correctly predicts the instantaneous heat transfer is needed. The main problem is that the in-cylinder aerodynamic structure while operating in pneumatic mode may be very different from a conventional mode during compression and expansion strokes (intake and exhaust strokes remain unchanged). Because of the high pressure ratio that exists between the pneumatic charging port and the in-cylinder, the opening of the charging valve changes the in-cylinder internal aerodynamic structure and modifies the convective heat transfer process.

The second reason is that the efficiency optimization of the pneumatic hybrid requires accurate knowledge of incylinder pressure versus Crank Angle, in order to determine the optimum timings for opening and closure of the charging valve [11]. Thus, the heat transfer model used has to accurately predict the instantaneous heat transfer flux as a function of Crank Angle, in order to correctly compute the cylinder pressure that directly determines the optimum timings.

Accordingly, the required heat exchange model must firstly predict the total heat exchange during compression and expansion strokes, and secondly describe as precisely

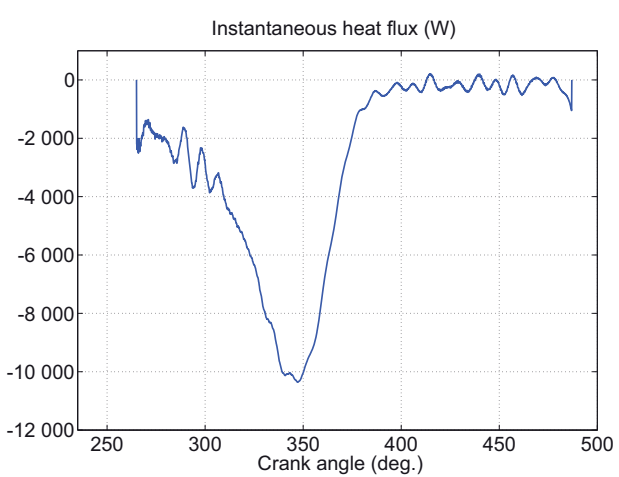

Figure 2

Heat transfer flux obtained during a supercharged mode without combustion

as possible the instantaneous heat flux as function of Crank Angle.

Experimental plots of instantaneous heat transfer flux versus Crank Angle, for different pneumatic modes and operating parameters, constantly show an atypical shape compared to that encountered in the well-known combustion mode. Figure 2 displays such an example for the pneumatic supercharged mode without combustion (ignition not performed). The Crank Angle reference is defined at exhaust TDC. As we shall see, such an asymmetric shape which is shifted from TDC cannot be predicted by the Woschni model in its original formulation. It is therefore necessary to modify the model, and to verify that the proposed model remains valid under various operating conditions.

The present work focuses on the motored mode and the supercharged mode without combustion. Pneumatic pump and motor modes are not investigated, because of the long duration of the charging valve opening (open thermodynamic system) that does not allow computation of the heat transfer flux during this period.

The paper is organized as follows. First, the classical calculations of gas temperature, instantaneous heat transfer, and the assumptions made by Woschni to build his frequently used correlation are recalled. The heat transfer for several motored engine conditions is then investigated. This study leads us to propose a new form of the correlation. Lastly, the supercharged mode is investigated using the adapted form of the Woschni model.

\section{IN-CYLINDER PRESSURE BASED CALCULATION OF THE HEAT FLUX AND OF THE HEAT TRANSFER COEFFICIENT}

\subsection{Instantaneous Heat Transfer}

Figure 3 depicts the in-cylinder context for application of the first law of thermodynamics:

$$
d U=\delta W+\delta Q+d H_{i}
$$




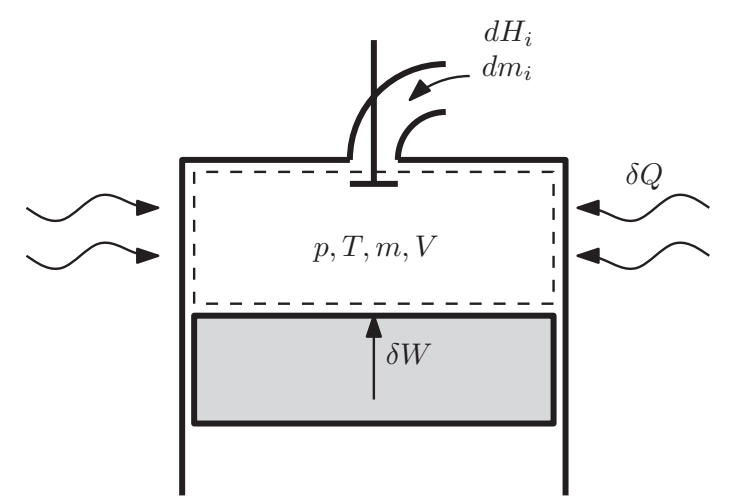

Figure 3

In-cylinder context for application of the first law of thermodynamics.

By rearranging (Eq. 1), using Joule's law $\left(U=m \cdot c_{v} \cdot T+U_{0}^{*}\right)$ and the ideal gas law, the instantaneous heat transfer flux can be determined:

$$
\frac{\delta Q}{d t}=\frac{1}{\gamma-1}\left[\gamma p \frac{d V}{d t}+V \frac{d p}{d t}\right]-c_{p} T_{i}^{0} \frac{d m_{i}}{d t}
$$

In the special case where the system is closed $\left(d m_{i}=0\right)$, which is the case if all valves are closed and blow-by gases are neglected [14], the global heat transfer flux can be simply determined by the in-cylinder pressure measurement. Otherwise, in the case of an open system, the mass flow rate $\frac{d m_{i}}{d t}$ and the stagnation temperature $T_{i}^{0}$ of flowing gases have to be known in order to determine the heat transfer rate.

\subsection{Heat Transfer Model}

Applying the assumption of steady convective heat transfer, the heat flux can be calculated by Newton's law:

$$
\frac{d Q(\theta)}{d t}=h(\theta) \cdot A\left[T-T_{w}\right]
$$

$\theta$ is the Crank Angle. $h(\theta)$ is the empirical heat transfer coefficient which is assumed to be the same for the entire heat transfer surface $\mathrm{A}$ at the mean temperature $T_{w}$. The incylinder gas temperature $T$ is determined using the ideal gas law:

$$
T=\frac{p V}{m R}
$$

Over the last 50 years, many authors have proposed several correlations to compute $h$. One family of correlations is based on a Stanton number correlation $[12,13]$, but the large majority of available models are based on a Nusselt number correlation [14-17]:

$$
N u=\frac{h \cdot L_{c}}{k}
$$

The most commonly used model is that of Woschni [14], and is based on a Nusselt number correlation suitable for forced convection in turbulent pipe flow:

$$
N u=K_{1} R e^{m}
$$

$K_{1}$ is a tunable coefficient, and a suitable value for $m$ under a forced convection turbulent flow is 0.8 . Woschni then introduces three correlations for the Reynolds Number, thermal conductivity and dynamic viscosity of the fluid:

$$
\begin{aligned}
R e & =\frac{1}{\mu} \rho w L_{c} \\
k & =K_{2} T^{0.75} \\
\mu & =K_{3} T^{0.62}
\end{aligned}
$$

Considering the bore $d$ as the characteristic length $L_{c}$, rearrangement of the previous equations gives:

$$
h=C \cdot d^{m-1} p^{m} w^{m} T^{0.75-1.62 m}
$$

$C$ is the final tunable coefficient, and $w$ is the average cylinder gas velocity. For a four stroke direct injection CI engine without swirl, Woschni proposes:

$$
w=C_{1} \bar{V}+C_{2} \frac{V_{d} T_{r}}{p_{r} V_{r}}\left(p-p_{m}\right)
$$

$V_{d}$ is the displaced volume, $p$ is the instantaneous cylinder pressure, $p_{m}$ is the motored cylinder pressure at same Crank Angle as $p . p_{r}, V_{r}$ and $T_{r}$ are respectively the pressure, volume and temperature at a reference point (i.e. intake valve closing). When combustion does not occur, which is the case considered here, the $C_{2}$ coefficient has to be set to zero, and Woschni assumes the cylinder gas velocity $w$ to be constant during compression and expansion, and to depend only on mean piston speed through the tunable coefficient $C_{1}$. This strong hypothesis is of course valid only if no swirl or no tumble exists.

\section{PNEUMATIC HYBRID ENGINE, INSTRUMENTATION AND CONTROL}

The pneumatic hybrid engine used for experiments is a prototype single cylinder, $347 \mathrm{~cm}^{3}$ displacement, 4-Stroke, Spark-Ignition, indirect fuel injection, with hemispherical cylinder head and flat piston. Table 1 gives the general engine dimensions and Table 2 gives the specifications of the valves, pipes and actuators. All measurements are taken in Crank Angle domain (10 samples per $\mathrm{CA}^{\circ}$ ). Incylinder pressure is measured by a piezoelectric pressure sensor. The intake, charging and exhaust port pressures are measured by three absolute piezo-resistive sensors. Intake air port temperature is measured by a Pt100 sensor, and exhaust and charging port temperatures are measured by two 
K-thermocouples. The intake and charging mass flow rates are measured with two mass flow controllers. The exhaust pressure is regulated by a valve. The intake and charging air can be warmed up by two resistive heaters. Two plenums of around 30 liters volume are mounted on both intake and exhaust lines. Temperature controls are implemented on both water and oil circuits $\left(80^{\circ} \mathrm{C}\right.$ regulated).

\section{TABLE 1}

Prototype engine dimension

\begin{tabular}{|c|c|}
\hline Bore & $79.5 \mathrm{~mm}$ \\
Stroke & $70 \mathrm{~mm}$ \\
Connecting rod length & $129 \mathrm{~mm}$ \\
Compression ratio & 9.1 \\
Air tank volume & $50 \mathrm{e}-3 \mathrm{~m}^{3}$ \\
\hline
\end{tabular}

TABLE 2

Valve and pipe specifications

\begin{tabular}{|c|c|c|c|}
\hline & Intake & Exhaust & Charging \\
\hline Number of valve & 2 & 1 & 1 \\
\hline Valve diameter $(\mathrm{mm})$ & 30.35 & 31.7 & 12 \\
\hline Actuator & Camshaft & Camshaft & $\begin{array}{c}\text { Electric } \\
\text { linear motor }\end{array}$ \\
\hline Pipe diameter $(\mathrm{mm})$ & 42.4 & 38 & 18 \\
\hline Pipe length $(\mathrm{mm})$ & 360 & 1500 & 1200 \\
\hline Valve opening angle (deg) & 707 & 487 & fully variable \\
\hline Valve closing angle (deg) & 215 & 15 & fully variable \\
\hline Maximum lift $(\mathrm{mm})$ & 9.21 & 10 & 4.8 \\
\hline
\end{tabular}

\section{MOTORED ENGINE TESTS}

\subsection{Method and Results}

Table 3 presents the experiments conducted in motored mode. Experiments \#1 to \#4 (respectively \#5 to \#10) were conducted at an intake air temperature near $20^{\circ} \mathrm{C}$ (respectively near $60^{\circ} \mathrm{C}$ ), for an engine revolution speed varying from 1000 to 2500 RPM (respectively 1000 to 3500 RPM). For all experiments, the intake and exhaust mean pressure value was 1 bar.

For each test, the following method was applied: the in-cylinder pressure was first computed as an average of 100 consecutive engine cycles. Next, the obtained pressure signal was low-pass filtered in order to reduce the noise. The cutting frequency was chosen while minimizing noise autocorrelation.

Secondly, the measured instantaneous heat flux was determined using Equation (2), from Intake Valve Closing (IVC) to Exhaust Valve Opening (EVO). The measured total heat transfer during compression and expansion strokes was then determined:

$$
\Delta Q_{I V C \rightarrow E V O, \text { measured }}=\int_{I V C}^{E V O} d Q
$$

TABLE 3

Test conditions in motored mode

\begin{tabular}{|c|c|c|c|c|}
\hline Exp. & $N(\mathrm{RPM})$ & $T_{\text {int }}\left({ }^{\circ} \mathrm{C}\right)$ & $T_{\text {exh }}\left({ }^{\circ} \mathrm{C}\right)$ & $m_{\text {intake }}\left(\frac{\mathrm{g}}{\text { cycle }}\right)$ \\
\hline 1 & 1000 & 20.4 & 18 & 0.346 \\
2 & 1500 & 20.4 & 18 & 0.354 \\
3 & 2000 & 21.4 & 19.7 & 0.354 \\
4 & 2500 & 23.6 & 21 & 0.337 \\
\hline 5 & 1000 & 60.2 & 55.1 & 0.323 \\
6 & 1500 & 60.4 & 57.6 & 0.327 \\
7 & 2000 & 60.3 & 59.6 & 0.327 \\
8 & 2500 & 60.3 & 61.2 & 0.322 \\
9 & 3000 & 60.2 & 65.1 & 0.308 \\
10 & 3500 & 60.4 & 70.9 & 0.311 \\
\hline
\end{tabular}

Thirdly, in motored operation according to Equations (3), (10) and (11) the total heat transfer value predicted by the model can be expressed as:

$$
\Delta Q_{I V C \rightarrow E V O, \text { model }}=C C_{1}^{m} \int_{I V C}^{E V O} f(\theta) d \theta
$$

with:

$$
f(\theta)=d^{m-1} p^{m} \bar{V}^{m} T^{0.75-1.62 m} A\left(T-T_{w}\right)
$$

To fulfill the energy balance $\Delta Q_{I V C \rightarrow E V O \text {,model }}$ has to be equal to $\Delta Q_{I V C \rightarrow E V O \text {,measured }}$, thus the tunable standard Woschni coefficients were determined together in the following expression:

$$
C * C_{1}^{m}=\frac{\Delta Q_{I V C \rightarrow E V O, \text { measured }}}{\int_{I V C}^{E V O} f(\theta) d \theta}
$$

Given the quite low value of total heat transfer measured, the mean surface temperatures of cylinder walls, cylinder head and piston $T_{w}$ were assumed to be equal to the water circuit temperature.

Finally, the Normalized Root Mean Square Error (NRMSE) was computed in order to evaluate the accuracy of the fit.

$$
N R M S E=\frac{\sqrt{\frac{\sum_{i=1}^{n}\left[d Q_{i}-d Q_{\text {model }, i}\right)^{2}}{n}}}{d Q_{\max }-d Q_{\min }}
$$

Table A.1 in Appendix A gives the complete numerical results. Appendix B gives the instantaneous measured and computed heat transfer rate as function of Crank Angle. Figure 4 depicts the indicated work $W_{i}$ per an entire cycle compared to the total heat transfer value $\Delta Q_{I V C \rightarrow E V O}$. Figure 5 displays the $C * C_{1}^{m}$ and NRMSE values. Figure 6 illustrates for Experiment \#2 the typical shape of instantaneous heat transfer flux obtained.

Firstly, an analysis of Figure 4 and Table A.1 (Appendix A) clearly shows that the total heat transfer magnitude is comparable to the Indicated Work per entire cycle, and thus is a first order factor on the energy balance. 


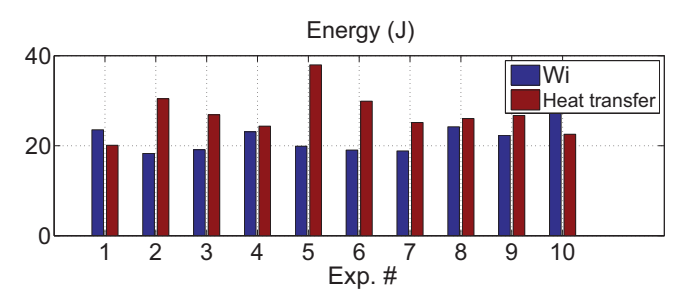

Figure 4

Indicated work and total heat transfer in motored mode.
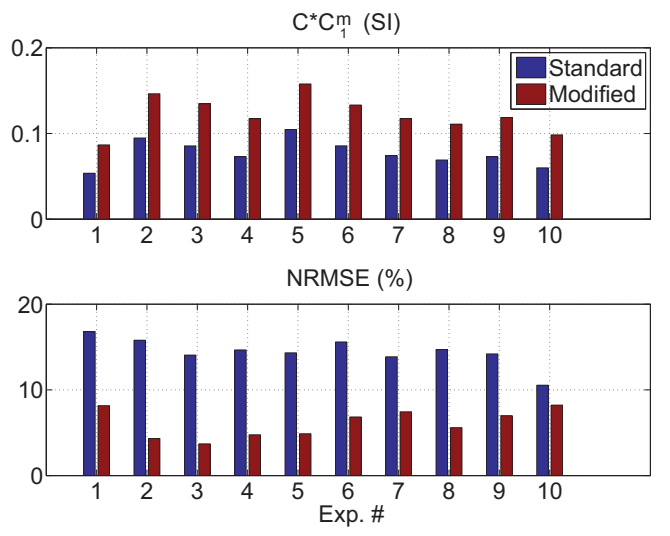

Figure 5

Standard and modified Woschni coefficients and NRMSE values in motored mode.

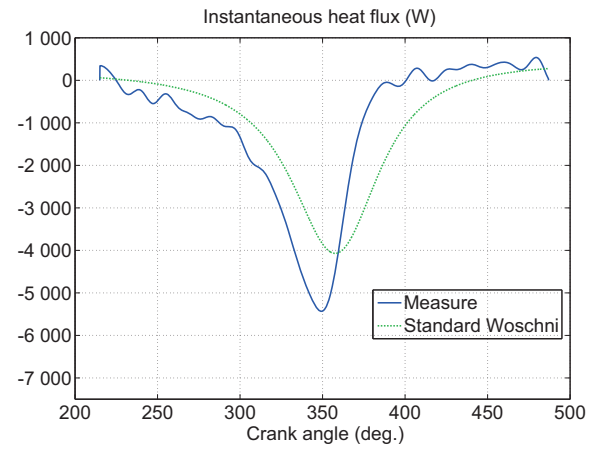

Figure 6

Instantaneous heat flux in motored test \#2 (1500 RPM, $T_{i n t}=20^{\circ} \mathrm{C}$ ).

Secondly, the high values of NRMSE displayed in Figure 5 show that, despite an exact total heat transfer value imposed by the method, the Woschni model is not suitable for predicting instantaneous value of heat flux. Figure 6 visually illustrates this phenomenon.

\subsection{Discussion on Instantaneous Heat Flux}

The shapes of all the instantaneous heat fluxes computed with the Standard Woschni model are unsuitable for describing the measured ones. Due to the assumptions made in the model (see Sect. 1.2), the standard Woschni function presents a peak of heat flux near TDC, and the curve is almost symmetric between the compression and the expansion strokes. All the measured curves of instantaneous heat flux present a peak near $350 \mathrm{CA}^{\circ}$. After this peak, the curve is asymmetric and increases rapidly up to a null value obtained near $375 \mathrm{CA}^{\circ}$.

This shape of the instantaneous heat flux curve during a motored test, i.e. asymmetric and shifted from TDC, has already been experimentally observed for both Spark Ignition [18] and Compression Ignition engines [19-21].

Many papers show, through Particle Image Velocimetry and Laser Doppler Velocimetry measurements, that the reason for this phenomenon is a modification of the in-cylinder air motion (tumble or swirl) during compression and expansion strokes:

For an SI engine with flat piston and hemispherical cylinder head, many studies [22-26] show tumble formation during intake and the first part of compression strokes, and its decay and destruction process approaching TDC.

For CI Direct Injection Engine, papers [27, 28] show that the swirl intensity is growing during compression stroke up to maximum near TDC. and then decreases during expansion.

A work by $\mathrm{Wu}$ and Perng [29] examined instantaneous heat flux through Large Eddy Simulation analysis, and compared the results with experimental measurements. They considered a pancake chamber with two different piston configurations: flat piston (a typical SI engine) and deep bowl piston (a typical DI Diesel). For the SI configuration, the in-cylinder vortex (tumble) is maximum at $90 \mathrm{CA}^{\circ}$ before TDC. and the heat flux peak is obtained around $25 \mathrm{CA}^{\circ}$ Before TDC. Authors show that this phenomenon is due a high temperature gradient obtained for this crank angle, combined with a tumble vortex generating strong velocity along the cylinder head surface. For the DI Diesel configuration, the heat flux peak is obtained at $5 \mathrm{CA}^{\circ}$ before TDC. The reason is the maximum swirl velocity obtained inside the bowl for this crank angle, combined with a strong squish motion along the cylinder head.

\subsection{Modified Woschni Model}

To take into account the change of in-cylinder air motion during compression and expansion, that causes the asymmetrical shape shifted from TDC. of the instantaneous heat flux curve, a modification of the Woschni model is now proposed.

The main idea is no longer to consider the average cylinder gas velocity $w$ as a constant during the full compression and expansion strokes, but to reduce $w$ near TDC. to account for the tumble decay and destruction. A sigmoid function 


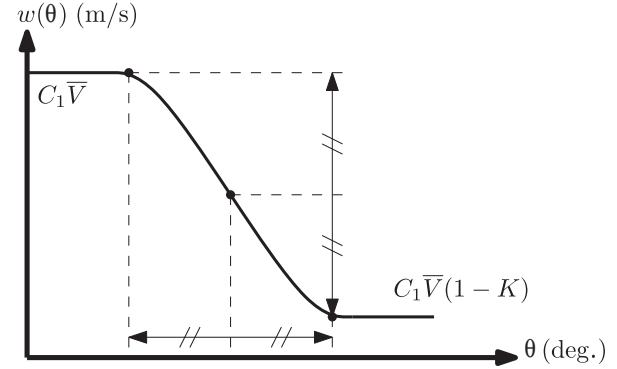

Figure 7

Schematic representation of the sigmoid gas velocity function.

was chosen for that purpose, and the new proposed expression for $W$ is then:

$$
w(\theta)=C_{1} \bar{V}\left[1-\frac{K}{1+e^{-\lambda(\theta-\alpha)}}\right]
$$

Figure 7 displays schematic representation of the sigmoid gas velocity function proposed. $K$ is the magnitude coefficient of velocity reduction, with:

$$
0<K<1
$$

If $K=1$, the average air velocity decreases down to zero, which is realistic in the case of total destruction of tumble near TDC. without swirl. $\alpha$ is the Crank Angle value for the symmetry point of the sigmoid function. $\lambda$ is the slope coefficient.

Given that the instantaneous heat flux presents a peak for a Crank Angle value near $350 \mathrm{CA}^{\circ}$, and is back to a null value for a Crank Angle near $375 \mathrm{CA}^{\circ}$, the coefficients were chosen arbitrarily and held constant: $K=1, \alpha=362.5 \mathrm{CA}^{\circ}$ and $\lambda=0.2$.

Exactly as for the Standard Woschni model, while using the above coefficient values for the sigmoid function, the $C * C_{1}^{m}$ coefficient was determined for each test, in order to obtain same value for measured and computed total heat transfer. Next, the fit accuracy is evaluated with a NRMSE computation.

Table A.2 in Appendix A presents the numerical results, and Appendix B presents the measured and computed instantaneous heat transfer as function as crank angle. Figure 5 displays the $C * C_{1}^{m}$ and NRMSE values compared to standard Woschni model. As an example, Figure 8 shows the measured and computed instantaneous heat flux curve using the standard and modified Woschni models.

Analysis of the NRMSE values displayed in Figure 5 clearly shows that in all cases the modified Woschni model constantly fits the experimental instantaneous heat flux curve better than the standard Woschni does, even while using constant sigmoid coefficients. The NRMSE mean

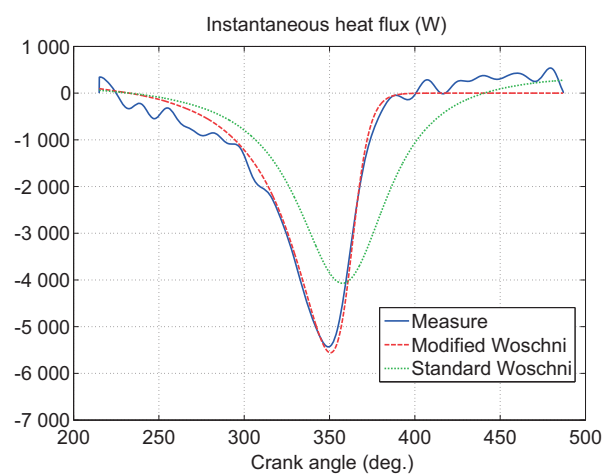

Figure 8

Comparison of instantaneous heat flux in motored test \#2 (1500 RPM, $T_{\text {int }}=20^{\circ} \mathrm{C}$ ).

value overall motored experiments for standard and modified models is respectively $14.45 \%$ and $6.09 \%$. One notes that the residual value of NRMSE is mainly due to the noise. Figure 8 visually illustrates the better fit obtained with the modified model compared to the standard one.

\subsection{Accuracy of the Heat Transfer Model Prediction in Motored Mode}

In order to be embedded in a full model of a pneumatic hybrid engine, the $C * C_{1}^{m}$ coefficient has to be chosen only once for robustness and simplicity.

In this part it is proposed to choose constant value for $C *$ $C_{1}^{m}$ coefficient, and while using this value, to evaluate the predictive accuracy of the model.

Because the instantaneous heat flux is not a linear function, we decided to find optimum value for the $C * C_{1}^{m}$ that minimize the absolute difference between measured and computed total heat transfer values over all the experiments. Respective values of 0.0730 and 0.1171 (SI Unit) were found for the Standard and the Modified model. Next, the predicted total heat transfer during compression and expansion using optimum value $C * C_{1}^{m}$, were determined and compared to the measured one.

Figure 9 shows the measured and predicted total heat transfer and NRMSE values and Table A.5 gives the complete numerical results (Appendix A).

First, an analysis of Table A.5 (Appendix A) and Figure 9 shows that the predicted total heat transfer values are fully comparable between the standard and modified models. Over all the experiments, the mean and maximum relative errors for predicted total heat transfer are respectively $-2.10 \%$ and $+36.03 \%$ for the standard model, and $-1.40 \%$ and $+35.13 \%$ for the modified one. Such high maximum relative error values are often encountered in this kind of study because of the complexity of the in-cylinder air motion 
TABLE 4

Test conditions in supercharged mode

\begin{tabular}{|c|c|c|c|c|c|c|c|c|}
\hline Exp. & $\begin{array}{c}P_{\text {tank }} \\
(\mathrm{bar})\end{array}$ & $\begin{array}{c}T_{\text {tank }} \\
\left({ }^{\circ}\right)\end{array}$ & $\begin{array}{c}T_{\text {int }} \\
\left({ }^{\circ}\right)\end{array}$ & $\begin{array}{c}T_{\text {exh }} \\
\left(^{\circ}\right)\end{array}$ & $\begin{array}{c}m_{\text {int }} \\
(\mathrm{g} / \text { cycle })\end{array}$ & $\begin{array}{c}m_{\text {chg }} \\
(\mathrm{g} / \text { cycle })\end{array}$ & $\begin{array}{c}\text { CVO } \\
(\mathrm{CA})\end{array}$ & $\begin{array}{c}\text { CVC } \\
(\mathrm{CA})\end{array}$ \\
\hline 1 & 8 & 116 & 24.8 & 22.3 & 0.3560 & 0.3333 & 235 & 265 \\
2 & 8 & 11 & 26.8 & 11.9 & 0.3610 & 0.3867 & 235 & 265 \\
\hline 3 & 5 & 100 & 24.6 & 31 & 0.3550 & 0.1267 & 235 & 260 \\
4 & 5 & 108 & 24.8 & 29.1 & 0.3557 & 0.2000 & 235 & 267 \\
5 & 5 & 116 & 24.8 & 25.3 & 0.3560 & 0.2667 & 235 & 275 \\
6 & 5 & 121 & 24.9 & 23.4 & 0.3577 & 0.3167 & 235 & 280 \\
7 & 5 & 124 & 24.9 & 22.5 & 0.3580 & 0.3500 & 235 & 285 \\
\hline 8 & 5 & 28.3 & 24.4 & 28.9 & 0.35930 & 0.1533 & 235 & 260 \\
9 & 5 & 27.6 & 25 & 21.8 & 0.3597 & 0.2267 & 235 & 267 \\
10 & 5 & 28.3 & 24.9 & 15.2 & 0.3617 & 0.3100 & 235 & 275 \\
11 & 5 & 28.1 & 24.6 & 11.4 & 0.3623 & 0.3533 & 235 & 280 \\
12 & 5 & 27.4 & 24.5 & 7.9 & 0.3630 & 0.4100 & 235 & 285 \\
\hline
\end{tabular}

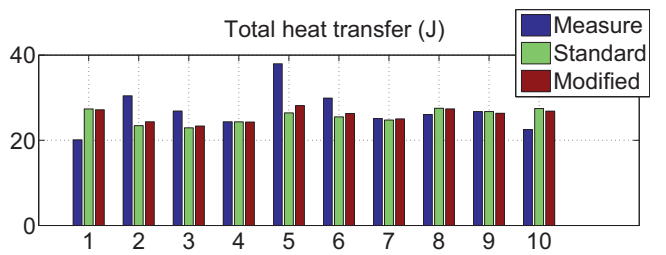

NRMSE (\%)

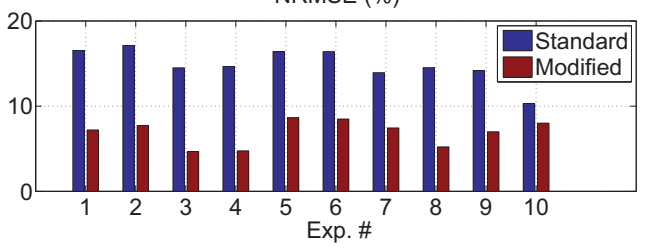

Figure 9

Predicted values of total heat transfer and NRMSE for both models compared to measurements in motored mode.

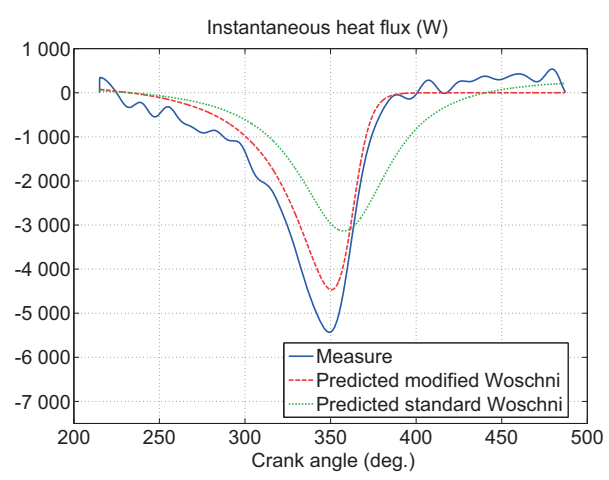

Figure 10

Measured and predicted instantaneous heat transfer in motored test Exp. \#2.

that may change abruptly in response to a small parameter change.
Second, the modified woschni model clearly better predicts the shape of instantaneous heat flux as function of Crank Angle. In the all experiments, the mean NRMSE value is respectively $14.86 \%$ and $6.91 \%$ for the standard and modified models. This is shown visually in Figure 10.

\section{SUPERCHARGED MOTORED MODE}

\subsection{Introduction}

This section studies the heat transfer while operating in pneumatic-supercharged mode without combustion, using only the modified Woschni model presented above. Given the high pressure ratio between the air tank and the cylinder, the opening of the charging valve probably modifies the internal aerodynamic structure created during the intake process. The question therefore arises as to how to ascertain whether the modified heat transfer model is still appropriate under these conditions.

In order to answer this question, the following tests were performed, for a fixed engine revolution speed of 1000 RPM. See Table 4.

A first set of tests consisted in varying the charging air temperature (a cold one of $10^{\circ} \mathrm{C}$ and a hot one of $115^{\circ} \mathrm{C}$ ) for a fixed tank pressure level (8 bar), fixed Charging Valve Opening $\left(\mathrm{CVO}=235 \mathrm{CA}^{\circ}\right)$ and fixed Charging Valve Closure $\left(\mathrm{CVC}=265 \mathrm{CA}^{\circ}\right)$.

A second set of tests consisted in varying $\mathrm{CVC}$ from $260 \mathrm{CA}^{\circ}$ up to $285 \mathrm{CA}^{\circ}$ (a value at which the total air mass flowed at the charging and intake valves are similar), for $\mathrm{CVO}$ fixed at $235 \mathrm{CA}^{\circ}\left(20 \mathrm{CA}^{\circ}\right.$ later than IVC) and at fixed tank pressure level ( 5 bar), but for two different temperatures $\left(25^{\circ} \mathrm{C}\right.$ and $\left.110^{\circ} \mathrm{C}\right)$.

\subsection{Results and Discussion}

For each test, the instantaneous and total heat transfer from CVC to EVO were calculated using a similar method to that 


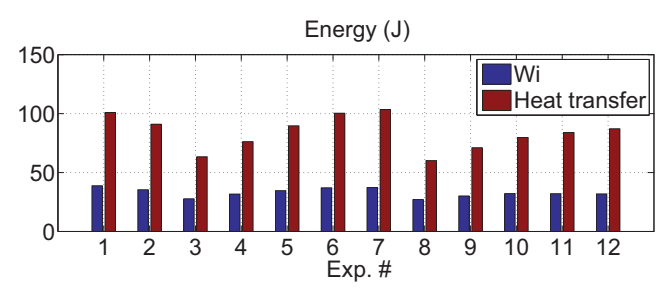

Figure 11

Measured indicated work and total heat transfer in supercharged mode.
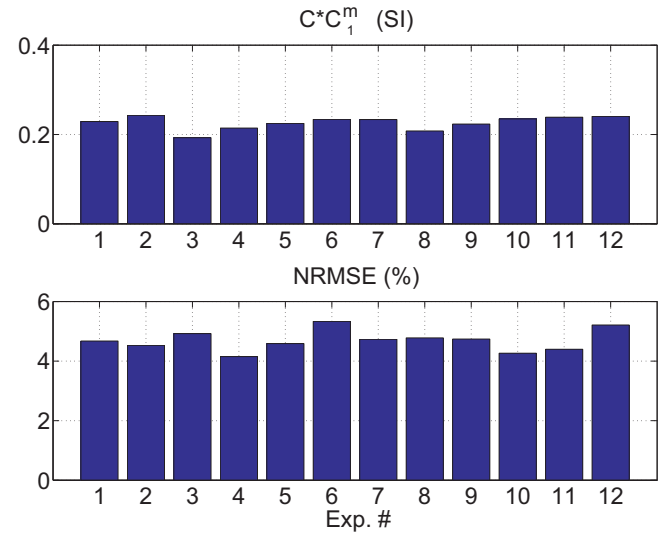

Figure 12

Modified Woschni coefficient and NRMSE values in supercharged mode.

presented for the motored test: the $C * C_{1}^{m}$ coefficient was determined in order to obtain same values for measured and computed total heat transfer.

During this optimization, the sigmoid coefficients were set at the same values as for the motored test: $(K=1$, $\alpha=362.5$ and $\lambda=0.2$ ). Figure 11 presents the measured total heat transfer and indicated work values per an entire cycle. Figure 12 displays the $C * C_{1}^{m}$ coefficient for each test. Figure 13 shows the instantaneous heat transfer flux versus Crank Angle for Experiment \#2, as an example. Table A.4 (Appendix A) gives the complete numerical results, and Appendix $\mathrm{C}$ presents the complete instantaneous heat transfer curves.

First, an analysis of Figure 11 shows that the supercharged mode increases total heat transfer compared to the motored mode, and thus remains a first order factor on energy balance.

Second, the NRMSE values depicted in Figure 12 show that the computed instantaneous heat transfer still correctly fits the measurement, while using the same sigmoid coefficient values as for motored test. Over all the supercharged tests, the NRMSE mean value of $4.69 \%$ was fully comparable to the value of $6.09 \%$ obtained in motored tests. This

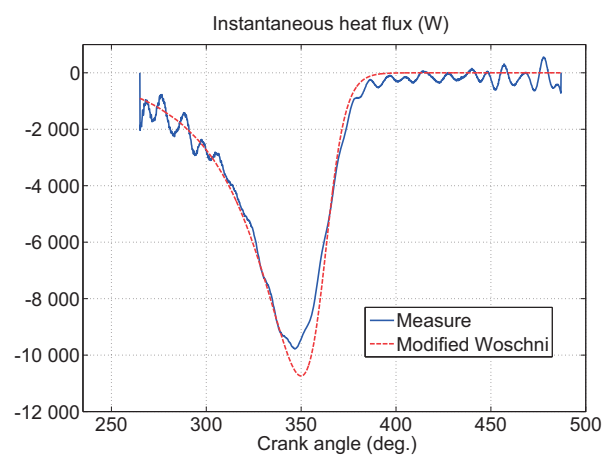

Figure 13

Instantaneous heat in supercharged test \#2 (1000 RPM, $p_{\text {tank }}=8$ bar, $T_{\text {int }}=26.8^{\circ} \mathrm{C}$ ).

is a key point regarding our aim, which is to develop an appropriate instantaneous heat transfer model, in order to correctly predict in-cylinder pressure. An example is given in Figure 13 showing the measured and computed instantaneous heat flux as function of crank angle for Experiment \#2.

Third, a comparison of the mean $C * C_{1}^{m}$ value between motored and supercharged mode shows an increase of $+57.8 \%$ and $+23.1 \%$. We conjecture that this increase is due to a stronger in-cylinder vortex created by the charging valve opening. Thus, the assumed higher tangential incylinder velocity along walls and cylinder head promotes the convective heat transfer process.

\subsection{Accuracy of Heat Transfer Model Prediction in Motored Supercharged Mode}

In this section, exactly as for the motored tests, the value chosen for $C * C_{1}^{m}$ was these that minimize, over all the tests, the absolute difference between measured and computed total heat transfer values. An optimum value of 0.5225 (SI Unit) was found. Next, for each supercharged test while using optimum value of $C * C_{1}^{m}$, the predicted instantaneous and total heat transfer were computed. Finally, the predicted total heat transfer and NRMSE values were computed in order to quantify the prediction accuracy.

Figure 14 displays the results, Table A.4 gives the complete numerical results. Figure 15 depicts an example of measured and predicted heat transfer for Experiment \#10.

In the all supercharged tests, the values observed for mean and maximum relative error of the predicted total heat transfer were respectively of $3.16 \%$ and $20.60 \%$. An NRMSE mean value of $5.60 \%$ is obtained. This value is slightly lower than the one obtained in motored mode $(6.91 \%)$ and is mainly due to the noise.

The assumed stronger aerodynamic structures created at the charging valve opening are probably the cause of the 

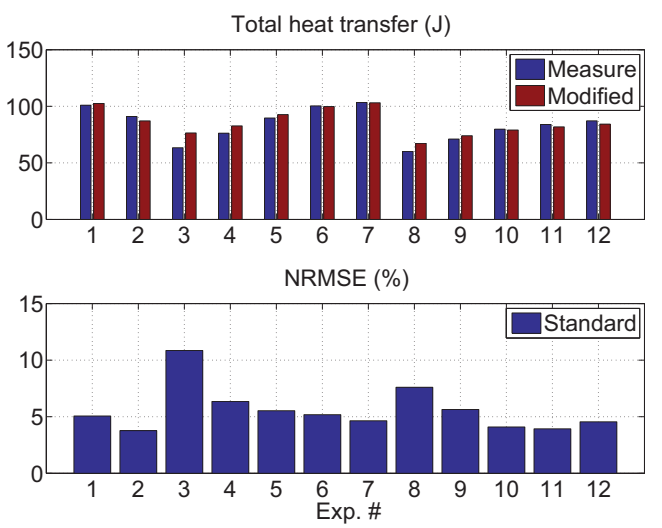

Figure 14

Predicted and measured total heat, NRMSE value in supercharged mode.

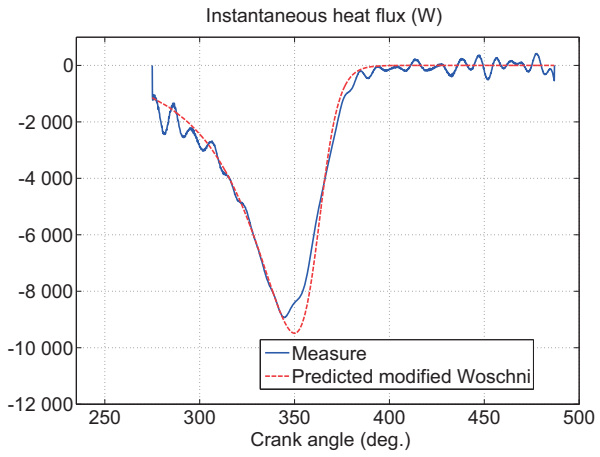

Figure 15

Predicted and measured instantaneous heat transfer in supercharged mode Exp. \#10.

smaller errors observed between supercharged and motored modes.

The low value of the error indicators obtained in this prediction study shows that the new modified model remains fully applicable and accurate under supercharged mode without combustion.

\section{FINAL VALIDATION}

In this section, a comparison of the model with a data set that has not been used for identify the model parameters is proposed. The considered test is a pneumatic supercharged mode without combustion. The intake pressure was 0.58 bar at an engine revolution speed of 2000 R.P.M. The thermodynamic state of the air tank was 5 bar at $285 \mathrm{~K}$. The charging valve timings $\left(\mathrm{CVO}=235 \mathrm{CA}^{\circ}, \mathrm{CVC}=290 \mathrm{CA}^{\circ}\right)$ were chosen in order to obtain a final in-cylinder air mass equivalent to those of an intake performed at 1 bar without pneumatic charge. The in-cylinder pressure after the pneumatic charge

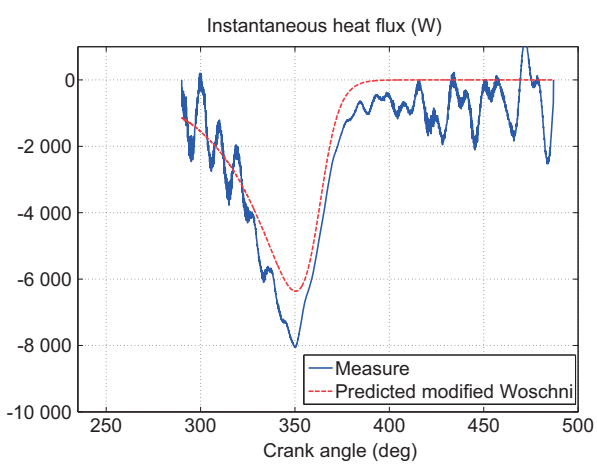

Figure 16

Predicted and measured instantaneous heat transfer in validation test.

is then comparable to a motored test presented in Section 3, but with a certainly different in-cylinder aerodynamic structure. While using the $C * C_{1}^{m}$ optimum coefficient identified for motored mode at an intake pressure of $1 \mathrm{bar}$, the predicted instantaneous heat transfer is computed and compared to the measurement. The measured and predicted total heat transfer values were respectively 35.64 and 25.00 joules $(-28.57 \%)$. A NRMSE value of $10.11 \%$ was obtained.

The relative error value of $-28.57 \%$ for predicted total heat transfer is comparable to these obtained while identifying the model parameters (See Tab. A.5 in Appendix A). The NRMSE value of $10.11 \%$ indicates that the shape of the predicted instantaneous heat transfer remains satisfactory. Figure 16 visually confirms this remark.

\section{CONCLUSION}

This work has proposed a modified model for instantaneous heat transfer while operating without combustion. Such a model is necessary for the accurate prediction of the incylinder pressure in a pneumatic hybrid engine. Because the instantaneous heat flux is primarily governed by in-cylinder air motion, the original form of the Woschni model is unable to describe the observed instantaneous heat transfer. A simple modification of the in-cylinder velocity function, by adding a sigmoid function that describe tumble extinction, leads to good predicted results compared to measurements. It has been shown that the proposed model, while using constant parameters, leads to satisfactory predicted results in comparison to the measured ones.

Future work will embed this modified heat transfer model into a complete one dimensional pneumatic hybrid engine simulation tool, and will investigate engine performances and determine optimum timings for the charging valve. 
APPENDIX A: COMPLETE NUMERICAL RESULTS

TABLE A.1

Numerical results for standard Woschni model in motored mode

\begin{tabular}{|c|c|c|c|c|}
\hline Exp. & $W_{i}(\mathrm{~J})$ & $\Delta Q_{I V C \rightarrow E V O}(\mathrm{~J})$ & $C * C_{1}^{m}(\mathrm{SI})$ & NRMSE $(\%)$ \\
\hline \hline 1 & -23.5 & -20.1 & 0.0536 & 16.8 \\
2 & -18.3 & -30.4 & 0.0947 & 15.7 \\
3 & -19.1 & -26.8 & 0.0855 & 14.0 \\
4 & -23.1 & -24.3 & 0.0730 & 14.6 \\
\hline 5 & -19.8 & -37.9 & 0.1047 & 14.3 \\
6 & -19.0 & -29.9 & 0.0856 & 15.5 \\
7 & -18.8 & -25.1 & 0.0742 & 13.8 \\
8 & -24.2 & -26.0 & 0.0691 & 14.7 \\
9 & -22.3 & -26.7 & 0.0730 & 14.1 \\
10 & -29.1 & -22.5 & 0.0599 & 10.5 \\
\hline
\end{tabular}

TABLE A. 2

Numerical results for modified Woschni model in motored mode

\begin{tabular}{|c|c|c|}
\hline Exp. & $C * C_{1}^{m}(\mathrm{SI})$ & NRMSE (\%) \\
\hline \hline 1 & 0.0866 & 8.1 \\
2 & 0.1464 & 4.3 \\
3 & 0.1347 & 3.7 \\
4 & 0.1174 & 4.7 \\
\hline 5 & 0.1578 & 4.8 \\
6 & 0.1332 & 6.8 \\
7 & 0.1177 & 7.4 \\
8 & 0.1109 & 5.5 \\
9 & 0.1188 & 6.9 \\
10 & 0.0983 & 8.2 \\
\hline
\end{tabular}

TABLE A.3

Measured and predicted total heat transfer in motored mode

\begin{tabular}{|c|c|c|c|c|c|}
\hline \multirow[t]{2}{*}{ Exp. } & \multirow{2}{*}{$\frac{\text { Measured }}{\Delta Q_{I V C \rightarrow E V O}(\mathrm{~J})}$} & \multicolumn{2}{|c|}{ Standard } & \multicolumn{2}{|c|}{ Modified } \\
\hline & & $\Delta Q_{I V C \rightarrow E V O}^{\text {pred,stand }}(\mathrm{J})$ & NRMSE $(\%)$ & $\Delta Q_{I V C \rightarrow E V O}^{\text {pred,mod }}(\mathrm{J})$ & $\operatorname{NRMSE}(\%)$ \\
\hline 1 & -20.1 & $\begin{array}{c}-27.3 \\
(+36.0 \%)\end{array}$ & 16.5 & $\begin{array}{c}-27.1 \\
(+35.1 \%)\end{array}$ & 7.2 \\
\hline 2 & -30.4 & $\begin{array}{c}-23.4 \\
(-22.9 \%)\end{array}$ & 17.1 & $\begin{array}{c}-24.3 \\
(-20.0 \%)\end{array}$ & 7.7 \\
\hline 3 & -26.8 & $\begin{array}{c}-22.9 \\
(-14.6 \%)\end{array}$ & 14.5 & $\begin{array}{c}-23.3 \\
(-13.0 \%)\end{array}$ & 4.6 \\
\hline 4 & -24.3 & $\begin{array}{c}-24.3 \\
(-0.1 \%)\end{array}$ & 14.6 & $\begin{array}{c}-24.2 \\
(-0.2 \%)\end{array}$ & 4.7 \\
\hline 5 & -37.9 & $\begin{array}{c}-26.4 \\
(-30.3 \%)\end{array}$ & 16.4 & $\begin{array}{c}-28.1 \\
(-25.7 \%)\end{array}$ & 8.6 \\
\hline 6 & -29.9 & $\begin{array}{c}-25.5 \\
(-14.7 \%)\end{array}$ & 16.4 & $\begin{array}{c}-26.2 \\
(-12.1 \%)\end{array}$ & 8.4 \\
\hline 7 & -25.1 & $\begin{array}{c}-24.7 \\
(-1.6 \%)\end{array}$ & 13.9 & $\begin{array}{l}-25.0 \\
(-0.5 \%)\end{array}$ & 7.4 \\
\hline 8 & -26.0 & $\begin{array}{c}-27.5 \\
(+5.6 \%)\end{array}$ & 14.5 & $\begin{array}{c}-27.3 \\
(+5.0 \%)\end{array}$ & 5.2 \\
\hline 9 & -26.7 & $\begin{array}{c}-26.7 \\
(+0.0 \%)\end{array}$ & 14.1 & $\begin{array}{c}-26.3 \\
(-1.4 \%)\end{array}$ & 6.9 \\
\hline 10 & -22.5 & $\begin{array}{c}-27.4 \\
(+21.7 \%)\end{array}$ & 10.3 & $\begin{array}{c}-26.8 \\
(+19.0 \%)\end{array}$ & 8.0 \\
\hline
\end{tabular}


TABLE A.4

Numerical results for modified model in supercharged mode

\begin{tabular}{|c|c|c|c|c|}
\hline Exp. & $W_{i}(\mathrm{~J})$ & $\Delta Q_{C V C \rightarrow E V O}(\mathrm{~J})$ & $C * C_{1}^{m}(\mathrm{SI})$ & NRMSE $(\%)$ \\
\hline 1 & -38.7 & -100.9 & 0.2291 & 4.6 \\
2 & -35.3 & -90.9 & 0.2430 & 4.5 \\
\hline 3 & -27.7 & -63.3 & 0.1929 & 4.9 \\
4 & -31.7 & -76.2 & 0.2144 & 4.1 \\
5 & -34.6 & -89.6 & 0.2250 & 4.5 \\
6 & -37.0 & -100.3 & 0.2339 & 5.3 \\
7 & -37.3 & -103.4 & 0.2335 & 4.7 \\
\hline 8 & -27.0 & -60.1 & 0.2080 & 4.7 \\
9 & -30.1 & -71.0 & 0.2234 & 4.7 \\
10 & -32.1 & -79.7 & 0.2350 & 4.2 \\
11 & -32.0 & -83.9 & 0.2388 & 4.3 \\
12 & -31.8 & -87.1 & 0.2407 & 5.2 \\
\hline
\end{tabular}

TABLE A.5

Measured and predicted mean-value total heat transfer in supercharged mode

\begin{tabular}{|c|c|c|c|}
\hline \multirow[t]{2}{*}{ Exp. } & \multirow{2}{*}{$\frac{\text { Measured }}{\Delta Q_{I V C \rightarrow E V O}(\mathrm{~J})}$} & \multicolumn{2}{|c|}{ Modified } \\
\hline & & $\Delta Q_{I V C \rightarrow E V O}^{\text {pred,mod }}(\mathrm{J})$ & NRMSE (\%) \\
\hline 1 & -100.9 & $\begin{array}{c}-102.5 \\
(+1.5 \%)\end{array}$ & 5.0 \\
\hline 2 & -90.9 & $\begin{array}{c}-87.1 \\
(-4.2 \%)\end{array}$ & 3.7 \\
\hline 3 & -63.3 & $\begin{array}{c}-76.4 \\
(+20.6 \%)\end{array}$ & 10.8 \\
\hline 4 & -76.2 & $\begin{array}{c}-82.6 \\
(+8.5 \%)\end{array}$ & 6.3 \\
\hline 5 & -89.6 & $\begin{array}{c}-92.6 \\
(+3.4 \%)\end{array}$ & 5.5 \\
\hline 6 & -100.3 & $\begin{array}{c}-99.7 \\
(-0.5 \%)\end{array}$ & 5.1 \\
\hline 7 & -103.4 & $\begin{array}{c}-103.0 \\
(-0.3 \%)\end{array}$ & 4.6 \\
\hline 8 & -60.1 & $\begin{array}{c}-67.2 \\
(+11.8 \%)\end{array}$ & 7.6 \\
\hline 9 & -71.0 & $\begin{array}{c}-73.9 \\
(+4.1 \%)\end{array}$ & 5.6 \\
\hline 10 & -79.7 & $\begin{array}{c}-78.9 \\
(-0.9 \%)\end{array}$ & 4.0 \\
\hline 11 & -83.95 & $\begin{array}{c}-81.80 \\
(-2.56 \%)\end{array}$ & 3.93 \\
\hline 12 & -87.1 & $\begin{array}{c}-84.2 \\
(-3.3 \%)\end{array}$ & 4.5 \\
\hline
\end{tabular}

Moreover, the present study has to be completed by experimental investigations of the in-cylinder aerodynamic structure during the charging valve opening. 
APPENDIX B: MOTORED MODE CURVES

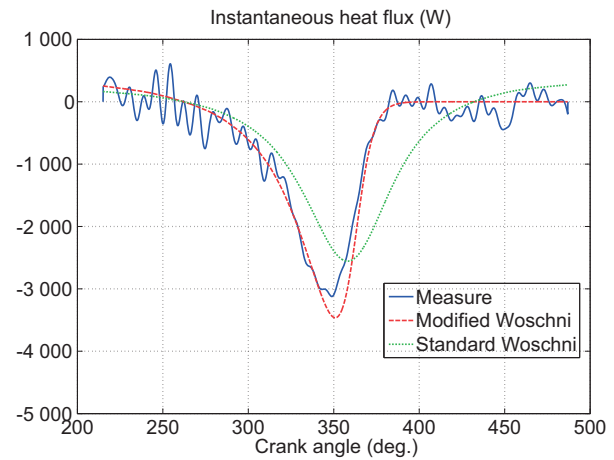

Figure B.1

Motored test Experiment \#1 (1000 RPM, $\left.T_{\text {int }}=20^{\circ} \mathrm{C}\right)$.

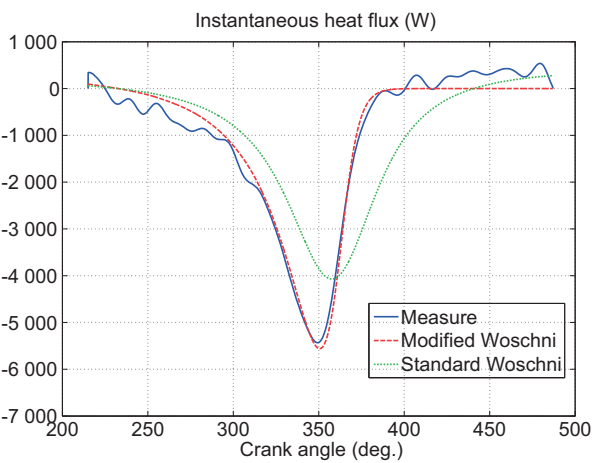

Figure B.2

Motored test Experiment \#2 (1500 RPM, $\left.T_{i n t}=20^{\circ} \mathrm{C}\right)$.

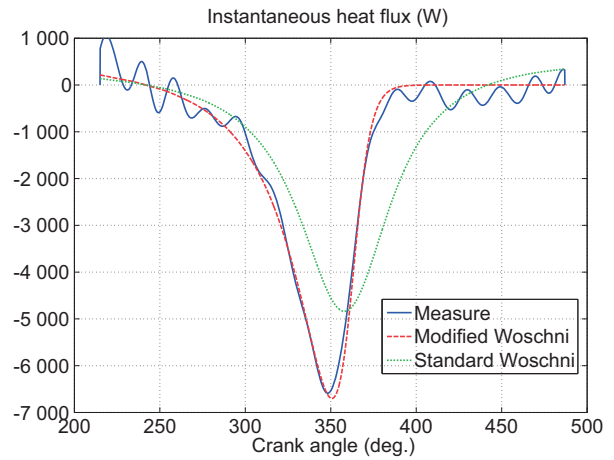

Figure B.3

Motored test Experiment \#3 (2000 RPM, $\left.T_{\text {int }}=20^{\circ} \mathrm{C}\right)$.

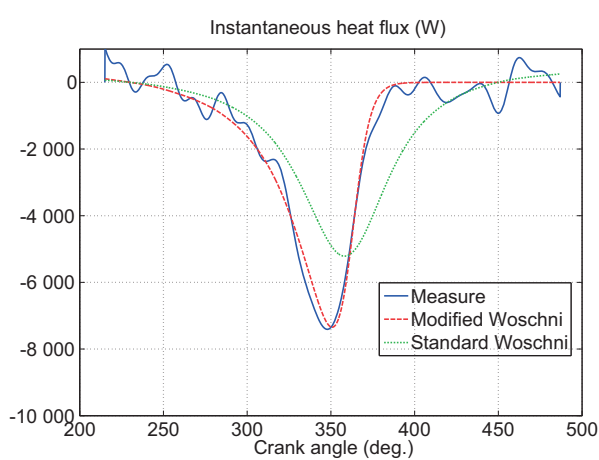

Figure B.4

Motored test Experiment \#4 (2500 RPM, $\left.T_{\text {int }}=20^{\circ} \mathrm{C}\right)$.

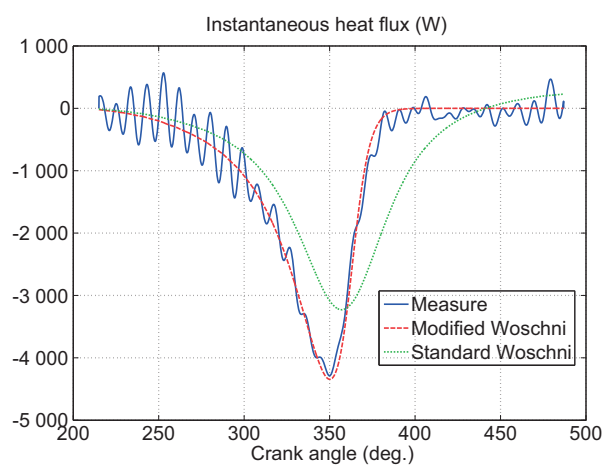

Figure B.5

Motored test Experiment \#5 (1000 RPM, $\left.T_{\text {int }}=60^{\circ} \mathrm{C}\right)$.

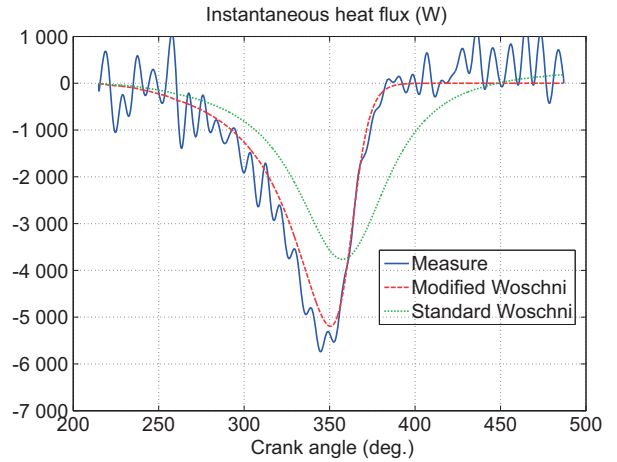

Figure B.6

Motored test Experiment \#6 (1500 RPM, $\left.T_{i n t}=60^{\circ} \mathrm{C}\right)$. 


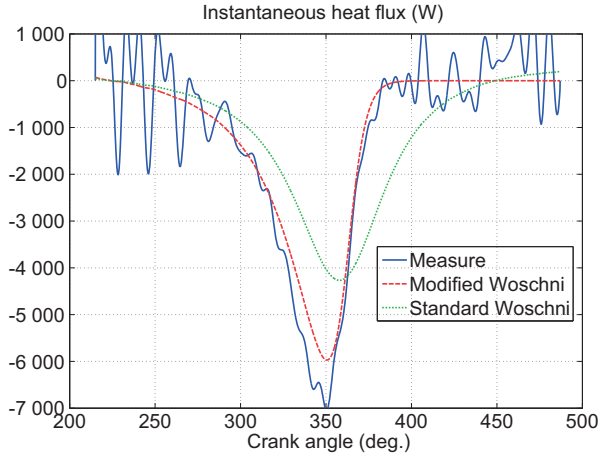

Figure B.7

Motored test Experiment \#7 (2000 RPM, $\left.T_{\text {int }}=60^{\circ} \mathrm{C}\right)$.

\section{APPENDIX C: SUPERCHARGED MODE CURVES}

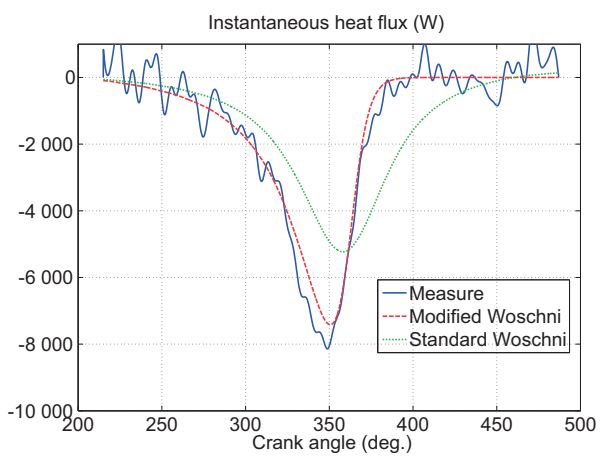

Figure B.8

Motored test Experiment \#8 (2500 RPM, $\left.T_{\text {int }}=60^{\circ} \mathrm{C}\right)$.

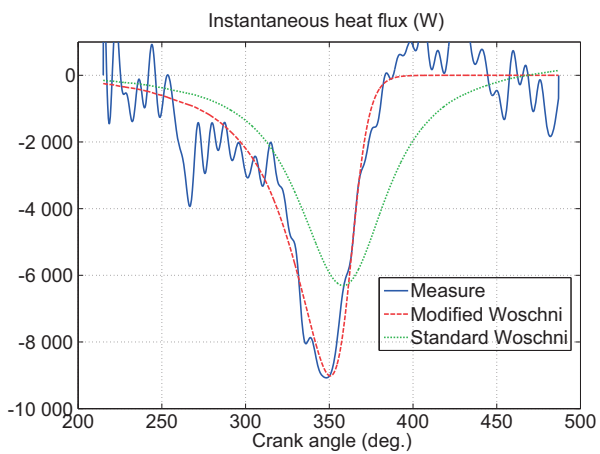

Figure B.9

Motored test Experiment \#9 (3000 RPM, $\left.T_{\text {int }}=60^{\circ} \mathrm{C}\right)$.

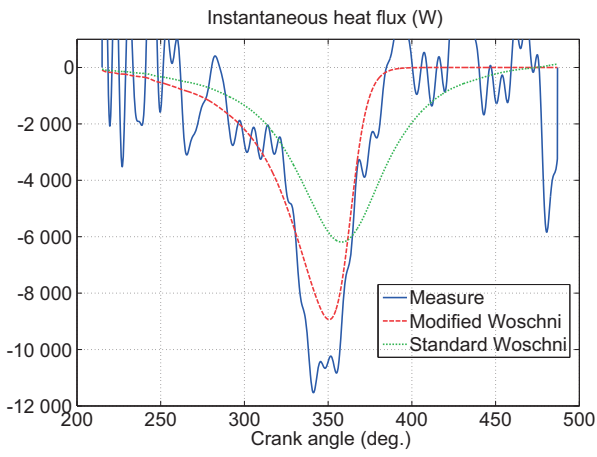

Figure B.10

Motored test Experiment \#10 (3500 RPM, $\left.T_{\text {int }}=60^{\circ} \mathrm{C}\right)$.

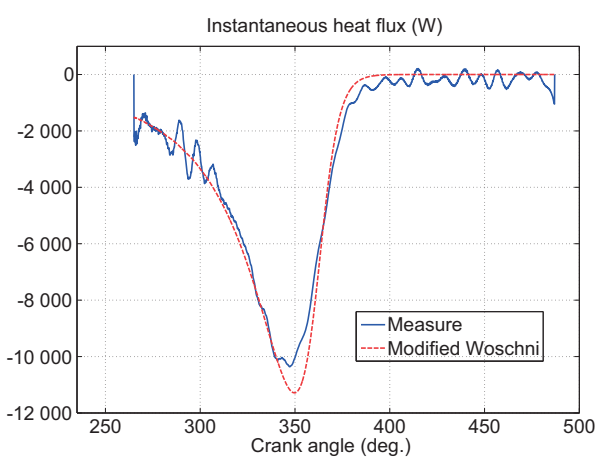

Figure C.1

Supercharged test Experiment \#1 (8 bar-hot).

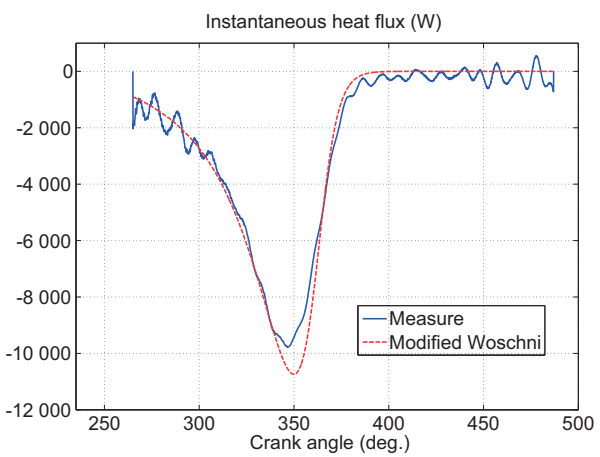

Figure C.2

Supercharged test Experiment \#2 (8 bar-cold). 


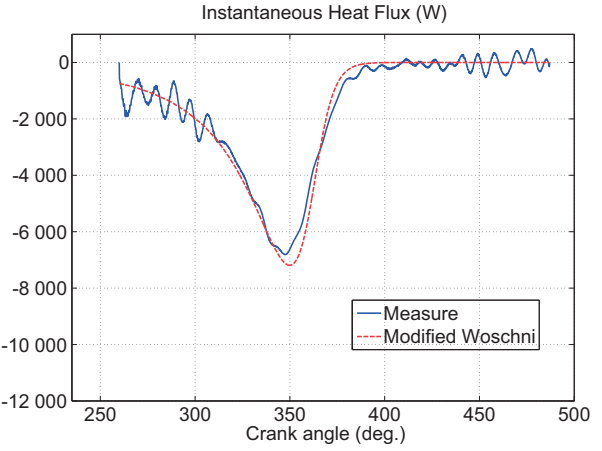

Figure C.3

Supercharged test Experiment \#3 (5 bar-hot, $\mathrm{CVC}=260 \mathrm{CA}^{\circ}$ ).

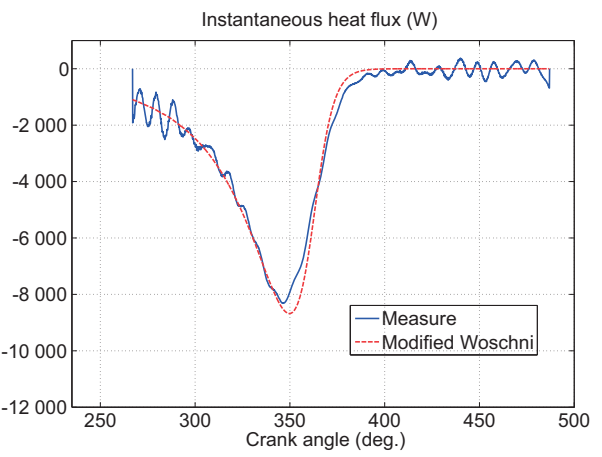

Figure C.4

Supercharged test Experiment \#4 $\left(5\right.$ bar-hot, $\left.\mathrm{CVC}=267 \mathrm{CA}^{\circ}\right)$.

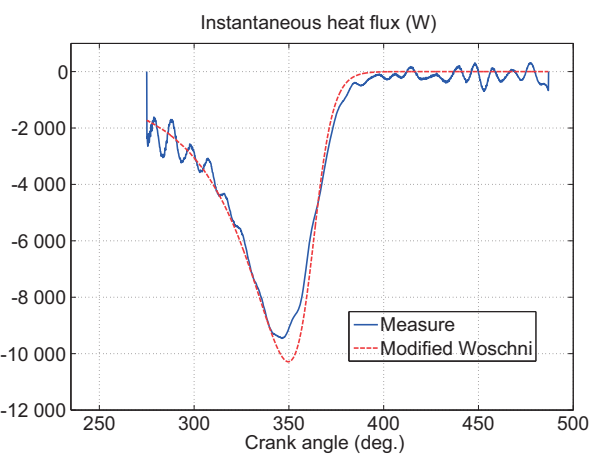

Figure C.5

Supercharged test Experiment \#5 (5 bar-hot, $\left.\mathrm{CVC}=275 \mathrm{CA}^{\circ}\right)$.

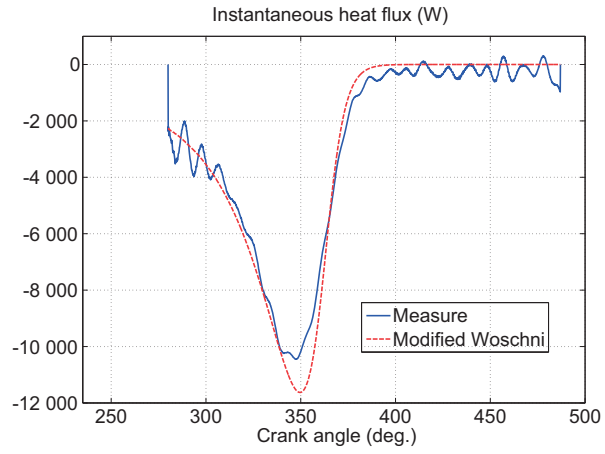

Figure C.6

Supercharged test Experiment \#6 (5 bar-hot, $\left.\mathrm{CVC}=280 \mathrm{CA}^{\circ}\right)$.

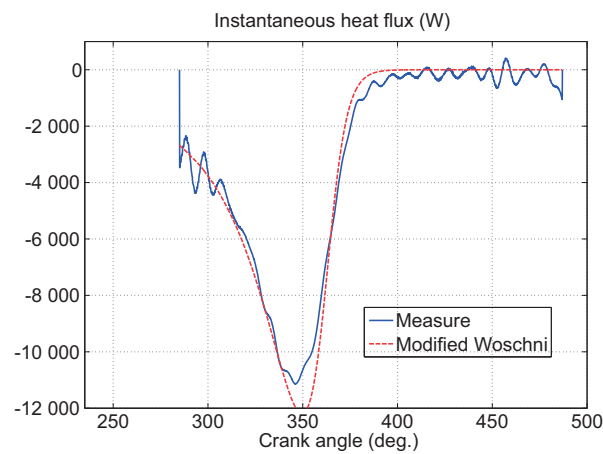

Figure C.7

Supercharged test Experiment \#7 (5 bar-hot, $\mathrm{CVC}=285 \mathrm{CA}^{\circ}$ ).

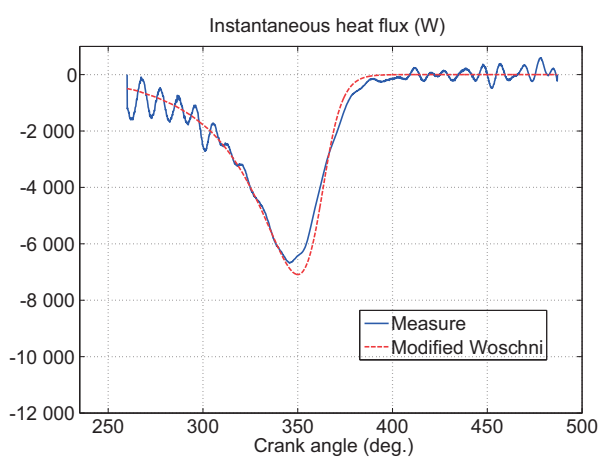

Figure C.8

Supercharged test Experiment \#8 (5 bar-cold, $\mathrm{CVC}=$ $260 \mathrm{CA}^{\circ}$ ). 


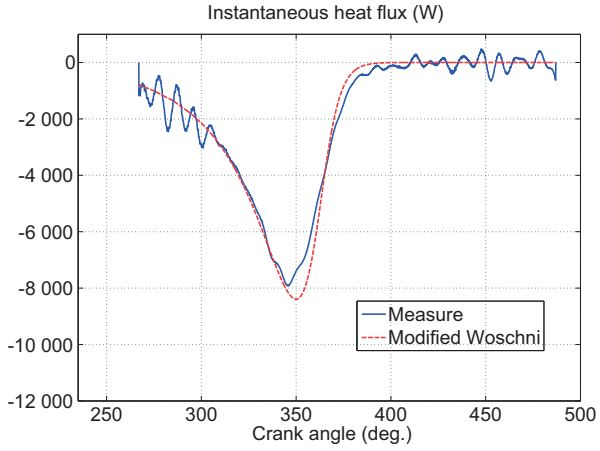

Figure C.9

Supercharged test Experiment \#9 (5 bar-cold, CVC = $267 \mathrm{CA}^{\circ}$ ).

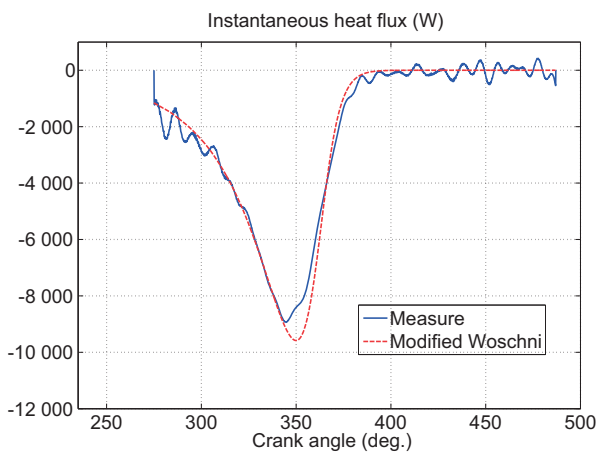

Figure C.10

Supercharged test Experiment \#10 (5 bar-cold, $\mathrm{CVC}=$ $275 \mathrm{CA}^{\circ}$ ).

\section{REFERENCES}

1 Schechter M. (1999) New cycles for automobile engines (1999) SAE Technical Paper 1999-01-0623.

2 Higelin P., Charlet A., Chamaillard Y. (2002) Thermodynamic Simulation of a Hybrid Pneumatic-Combustion Engine Concept, J. Appl. Thermodynamics 5, 1, 1-11.

3 Donitz C., Vasile I., Onder C., Guzzella L. (2009) Realizing a concept for high efficiency and excellent driveability: The downsized and supercharged hybrid pneumatic engine, $S A E$ paper 2009-01-1326.

4 Andersson M., Johansson B., Hultqvist A. (2005) An Air Hybrid for High Power Absorption and Discharge, SAE paper 2005-01-2137.

5 Tai C., Tsao T., Levin M.B., Schechter M.M. (2003) Using Camless Valvetrain for Air Hybrid Optimization, SAE paper 2003-01-0038.

6 Trajkovic S., Tunestal P., Johanssonn B. (2008) Investigation of Different Valve Geometries and Valve Timing Strategies and their Effect on Regenerative Efficiency for a Pneumatic Hybrid with Variable Valve Actuation, SAE paper 2008-01-1715.

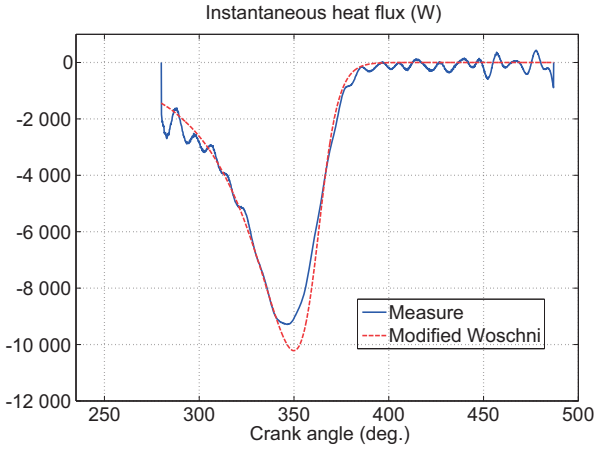

Figure C.11

Supercharged test Experiment \#11 (5 bar-cold, CVC = $\left.280 \mathrm{CA}^{\circ}\right)$.

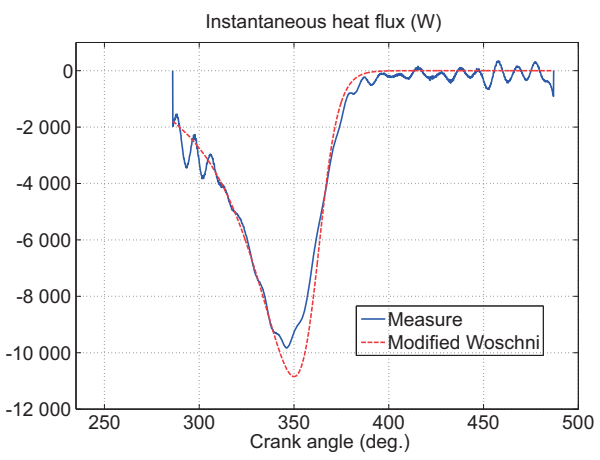

Figure C.12

Supercharged test Experiment \#10 (5 bar-cold, $\mathrm{CVC}=$ $286 \mathrm{CA}^{\circ}$ ).

7 Donitz C., Vasile I., Onder C., Guzzella L. (2009) Modelling and optimizing two- and four-stroke hybrid pneumatic engines Proc. IMechE Part D: J. Automobile Engineering 223, 2, 255280.

8 Ivanco A., Colin G., Chamaillard Y., Charlet A., Higelin P. (2009) Energy Management Strategies for a Pneumatic-Hybrid Engine Based on Sliding Window Pattern Recognition, Oil Gas Sci. Technol. - Rev. IFP 65, 1, 179-190.

9 Trajkovic S., Per T., Bengt J. (2010) Vehicle Driving Cycle Simulation of a Pneumatic Hybrid Bus Based on Experimental Engine Measurements, SAE paper 2010-01-0825.

10 Elgowainy A., Burnham A., Wang M., Molburg J., Rousseau A. (2009) Well-To-Wheels Use and Greenhouse Gas Emissions of Plug-in-Hybrid Electric Vehicles, SAE paper 2009-01-1309.

11 Brejaud P., Charlet A., Chamaillard Y., Ivanco A., Higelin P. (2009) Pneumatic-Combustion Hybrid Engine: A Study of the Effect of the Valvetrain Sophistication on Pneumatic Modes, Oil Gas Sci. Technol. - Rev. IFP 65, 1, 27-37. 
12 Wu Y.Y., Chen B.C., Hsieh F.C., Ke C.T. (2009) Heat transfer model for small-scale spark-ignition engines, Int. J. Heat Mass Trans. 52, 7-8, 1875-1886.

13 Thombare D.G., Verma S.K. (2008) Technological development in the Stirling cycle engines, Renew. Sust. Energ. Rev. 12, 1, 1-38.

14 Woshni G.A. (1967) Universally application equation for instantaneous heat transfer coefficient in internal combustion engine, SAE 76, 670931, 3065-3083.

15 Annand W.J.D. (1963) Heat transfer in the cylinders of reciprocating internal combustion engines, Proc. IMechE Part E: J. Process Mechanical Engineering 177, 973-990.

16 Eichelberg G. (1939) Some new investigations on old combustion engine problems, Engineering 148, 446-463; Engineering 148, 547-560.

17 Hohenberg G.F. (1979) Advanced approaches for heat transfer calculations, Diesel Engine Thermal Loading, SAE Technical paper SAE SP-449.

18 Yang J. (1988) Convective heat transfer predictions and experiments in an IC engine, PhD Thesis, University of WisconsinMadison.

19 Ohkubo Y., Ohtsuka M., Kato J., Kozuka K., Sugiyama K. (1984) Velocity measurements by back-scattered LDV, 4th Joint Symposium on Internal Combustion Engines.

20 Arcoumanis C., Cuttera P., Whitelawa D.S. (1998) Heat Transfer Processes in Diesel Engines, Chem. Eng. Res. Des. 76, 2, 124-132.

21 Sanli A., Ozsezen A.N., Kilicaslan I., Canakci M. (2007) The influence of engine speed and load on the heat transfer between gases and in-cylinder walls at fired and motored conditions of an IDI diesel engine, Appl. Therm. Eng. 28, 11-12, 1395-1404.
22 Li Y., Zhao H., Peng Z., Ladommatos N. (2001) Analysis of tumble and swirl motions in a Four-Valve SI Engine (2001), SAE Technical paper 2001-01-3555.

23 Arcoumanis C., Bae C.S., Hu Z. (1994) Flow and combustion in a Four-Valve Spark Ignitin Optical Engine, SAE Technical paper 940475.

24 Kang K.Y., Baek J.H. (1995) LDV measurement and analysis of tumble formation and decay in a four-valve engine, Exper. Therm. Fluid Sci. 11, 2, 181-189.

25 Huang R.F., Yang H.S., Yeh C.-N. (2008) In-cylinder flows of a motored four-stroke engine with flat-crown and slightly concave-crown pistons, Exper. Therm. Fluid Sci. 32, 5, 11561167.

26 Huang R.F., Huang C.W., Chang S.B., Yang H.S., Lin T.W., Hsu W.Y. (2005) Topological flow evolutions in cylinder of a motored engine during intake and compression strokes, $J$. Fluids Struct. 20, 1, 105-127.

27 Lin L., Shulin D., Jin X., Jinxiang W., Xiaohong G. (2000) Effetcs of combustion chamber geometry on in-cylinder air motion and performance in DI Diesel Engine, SAE Technical paper 2000-01-0510.

28 Kawashima J.I., Ogawa H., Tsuru Y. (1998) Research on a variable swirl Intake port for 4-valve Hi-speed DI Diesel Engines, SAE Technical paper 982680.

29 Wu H.W., Perng S.W. (2002) LES analysis of turbulent flow and heat transfer in motored engines with various SGS models, Int. J. Heat Mass Trans. 45, 11, 2315-2328.

Final manuscript received in March 2011 Published online in September 2011 